\title{
DETERMINATION OF THE APPROPRIATE VEHICLE OPERATING IN PARTICULAR URBAN TRAFFIC CONDITIONS
}

This paper presents selection of the most appropriate vehicle intended to operate on a particular urban territory, using the specific methods of multi-criteria analysis. For selecting the suitable vehicle, it is necessary to determine a number of specific criteria. In the paper, the desired vehicle is selected from five vehicles, while, each of them has a different product brand. To determine the weights of criteria, the Saaty pairwise comparison method is applied, and subsequently, the multi-criteria evaluation of alternatives is utilized for a research problem.

Keywords: Operation, supply, urban traffic, City logistics, vehicle, decision-making.

\section{Introduction}

Utility vehicle, i.e. vehicle used for the cargo supply in urban area, is an important factor and limitation for the customers' services in regard to the urban style of the city, city built-up area, the deployment of customers, etc. Generally, customers or distribution centers do not have any specific requirements for the transport means and are supplied by conventional freight vehicles.

However, each of the vehicles has distinct fuel consumption and their individual parameters differ. The deployment of the optimal vehicle can significantly facilitate the activities of the supply in a given territory. Thus, determining the appropriate vehicle for operating in a particular territory in the context of City logistics undoubtedly represents an essential aspect for individual enterprises [1 - 3].

\section{Issues of decision-making}

Determination of the weights and making the subsequent multi-criteria evaluation of alternatives can be considered to be a decision-making issue in which the final result is influenced by a group of external aspects [4 and 5].

For the purpose of solving the decision-making issues, the individual methods of multi-criteria analysis may be utilized [6, 7 and 8]. It is important to have a list of alternatives from which to select. Cases where a clearly defined list of potential alternatives is known are more or less the exception than the rule [7 and 9].

General procedure for the multi-criteria evaluation of alternatives includes six basic phases: (1) Identification of alternatives, (2) Determination of the specific criteria, (3) Determination of the weights of criteria, (4) Determination of the criteria examples, (5) Partial evaluation of alternatives and (6) Selection of the most appropriate alternative.

The analysis of existing methods utilized for dealing with the multi-criteria analysis has been carried out. Some of these methods do not take into consideration the weights of criteria. And since, among the criteria which influence the individual factors of the multi-criteria evaluation of alternatives, significant distinctions in the importance of criteria exist, these methods are not suitable for our particular research problem [7 and $10-14]$.

\subsection{Methods for determination of the weights of criteria}

Methods for determining the weights (see Table 1) can be divided according to the information that we have about the criteria significance [5-8, 13 and 14]:

- no information,

- ordinal information,

- cardinal information

\footnotetext{
* ${ }^{1}$ Ondrej Stopka, ${ }^{2}$ Branislav Sarkan, ${ }^{3}$ Maria Chovancova, ${ }^{4}$ Larisa M. Kapustina

${ }^{1}$ Department of Transport and Logistics, Faculty of Technology, Institute of Technology and Business in Ceske Budejovice, Czech Republic

${ }^{2}$ Department of Road and Urban Transport, Faculty of Operation and Economics of Transport and Communications, University of Zilina, Slovakia

${ }^{3}$ Department of Railway Transport, Faculty of Operation and Economics of Transport and Communications, University of Zilina, Slovakia

${ }^{4}$ Ural State University of Economics, Yekaterinburg, Russia

E-mail: stopka@mail.vstecb.cz
} 
No information - The researchers are not able to decide about the level of significance of the criteria. It is supposed that there is a criteria matrix quantified by the cardinal values.

Ordinal information - These methods suppose that the researcher may express the significance of each criterion by assigning to all criteria their special numbers or when comparing all criteria pairs, they may decide which criterion, from the current pair, is more important compared to another. In both cases, it is permissible to determine two or more criteria as equal.

Cardinal information - These methods suppose that the researcher may not only determine the order of criteria significance, but also the significance of the relationships among all criteria.

Methods for determination of the weights of criteria

Table 1

\begin{tabular}{|l|l|l|}
\hline \multicolumn{2}{|l|}{ Information about significance among the criteria pairs } \\
\hline No information & Ordinal information & $\begin{array}{l}\text { Cardinal } \\
\text { information }\end{array}$ \\
\hline Method of equal weights & Method of ranking & Scoring method \\
\hline Entropy method & Fuller method & Saaty method \\
\hline
\end{tabular}

Source: [10]

\subsection{Methods for the multi-criteria evaluation of alternatives}

Methods for the multi-criteria evaluation of alternatives (selection of the most suitable alternative) are divided according to the information about the significance between the criteria pairs that is required. The information may be [ 5 and 10]:

- maximizing the benefits,

- minimizing the distance from the ideal variant,

- $\quad$ regarding the preferential relationship.

Specific methods for the multi-criteria evaluation of alternatives include: Simple method of scoring or Simple method of ranking, Lexicographical method, Permutation method, ORESTE method, TOPSIS method, Weighted Sum
Approach - WSA method, Analytic Hierarchy Process - AHP method, Entropy method and many others [5 and $8-11]$.

\section{Research problem and outcomes}

This part of the paper deals with the research problem and obtained outcomes, i.e., the shortened and modified version of the general procedure for multi-criteria evaluation of alternatives. This version specifically consists of: (1) Determination of the specific criteria, (2) Identification of alternatives, (3) Determination of the weights of criteria and (4) Selection of the most appropriate alternative.

\subsection{Determination of the specific criteria}

Phase one of our modified procedure of multi-criteria evaluation of alternatives includes the decision about the specific criteria which influence the final evaluation process [8, 9 and 12].

Among the specific criteria regarding the selection of the most appropriate vehicle for the cargo supply in urban area, five of them, primarily due to the vehicles utility purposes, were defined. For these criteria, required data, concerning the parameters of further identified alternatives, were obtained [10 and 13].

For the purpose of the appropriate vehicle selection, the following criteria were therefore included: $K 1$ - the fuel consumption (engine diesel) of the vehicle in the city $(1 /$ $100 \mathrm{~km}), K 2$ - the price of the vehicle (CZK), K3 - the vehicle loading length $(\mathrm{mm}), K 4$ - the cargo space volume of the vehicle $\left(\mathrm{m}^{3}\right)$ and $K 5$ - the gross vehicle weight $(\mathrm{kg})$.

\subsection{Identification of alternatives}

Among the selected alternatives (utility vehicles - Di), commonly used means of transport for operation on the city territory produced by different manufacturers may be

Identified alternatives (vehicles) with respect to the specific criteriaTable 2

\begin{tabular}{|c|c|c|c|c|c|}
\hline Criteria $(K i)$ & $\begin{array}{c}K 1-\text { Fuel } \\
\text { consumption } \\
(1 / 100 \mathrm{~km})\end{array}$ & $\begin{array}{c}K 2 \text { - Price } \\
(\mathrm{CZK})\end{array}$ & K3 - Length $(\mathrm{mm})$ & $\begin{array}{c}K 4-\text { Cargo space } \\
\text { volume }\left(\mathrm{m}^{3}\right)\end{array}$ & $\begin{array}{c}K 5 \text { - Gross weight } \\
(\mathrm{kg})\end{array}$ \\
\hline Dehicle $(D i)$ & 9.1 & 489900 & 5048 & 10.80 & 2950 \\
\hline D2 & 7.8 & 328000 & 3450 & 7.05 & 1970 \\
\hline D3 & 8.5 & 724200 & 5998 & 14.00 & 3223 \\
\hline D4 & 9.5 & 505000 & 3250 & 9.50 & 2810 \\
\hline D5 & 13.5 & 547676 & 3400 & 8.70 & 2087 \\
\hline
\end{tabular}

Source: authors 
included. For the purpose of this paper, the following vehicles are chosen and with respect to the above-identified criteria, are characterized in the subsequent table (see Table 2): D1 Vehicle 1, D2 - Vehicle 2, D3 - Vehicle 3, D4 - Vehicle 4 and D5 - Vehicle 5.

\subsection{Determination of the weights of criteria using the particular method}

To determine the weights of criteria, Saaty pairwise comparison method was selected. A number of specific criteria have lesser or greater effect on vehicle determination. Thus, it was important to select such a method which enables the expert's judgment in order to decide about the relationship of significance among the criteria pairs. Furthermore, Saaty method enables the detailed distribution of these significances [12 - 14].

For the evaluation of the relationship of significance among the criteria pairs, Saaty method a nine point scale utilizes [5, 6 and 13]. 1 - equal criteria $i$ and $j, 3$ - slightly preferred criterion $i$ above $j, 5$ - strongly preferred criterion $i$ above $j, 7$ - very strongly preferred criterion $i$ above $j, 9$ absolutely preferred criterion $i$ above $j$ [5, 6 and 13].

It is possible to use intermediate values $(2,4,6,8)$ as well. Matrix elements $S=\left(s_{i j}\right)$ are interpreted as estimates of the fraction of the weights of the $i-t h$ and $j$-th criteria. The expert compares each pair of the criteria and writes the significance values of $i$-th in the relation to the $j$-th criterion in the Saaty matrix $S=\left(s_{i j}\right)$. In case that $j$-th criterion is preferred above the $i$-th criterion, inverse values are written in the Saaty matrix $(s$ $=1 / 3$ for low preference, $s_{i j}=1 / 5$ for strong preference, etc.) [10, 15 and 16].

Weight vector values are denoted as $v=\left(v_{p}, v_{2}, \ldots, v_{k}\right)$. The normalized geometric mean represents the most preferred method of the weight calculation. This process is generally called "logarithmic least squares method [14 - 16]." The normalized weights are calculated for each criterion when utilizing the geometric mean of each row in the matrix divided by the sum of the geometric means of all the criteria [10 and 14].

Calculation of the geometric mean of each row of the matrix $S$ is expressed in the following formula (1):

$g_{i}=\sqrt[k]{\prod_{j=1}^{k} S_{i j}} \ldots \ldots i, j=1,2, \ldots, k$

where $g_{i}$ is the geometric mean; $s_{i j}$ are elements of Saaty matrix; $\Pi$ represents the product of values of Saaty matrix elements.

Normalization of the geometric mean is shown in the formula (2):

$v_{i}=\frac{g_{i}}{\sum_{i=1}^{k} g_{i}}, \ldots \ldots i, j=1,2, \ldots, k$ where $v_{i}$ is the normalized (weighted) geometric mean, $g_{i}$ is the geometric mean, $\sum$ represents the sum of geometric mean values.

The individual values of the weights of criteria are summarized in Table 3.

Completed Saaty matrix (table)

Table 3

\begin{tabular}{|c|c|c|c|c|c|}
\hline Criteria $(K i)$ & $\mathrm{K} 1$ & $\mathrm{~K} 2$ & $\mathrm{~K} 3$ & $\mathrm{~K} 4$ & $\mathrm{~K} 5$ \\
\hline$K 1$ & 1 & 3 & 5 & $1 / 2$ & 5 \\
\hline$K 2$ & $1 / 3$ & 1 & 4 & $1 / 3$ & 7 \\
\hline$K 3$ & $1 / 5$ & $1 / 4$ & 1 & $1 / 7$ & 7 \\
\hline$K 4$ & 2 & 3 & 7 & 1 & 9 \\
\hline$K 5$ & $1 / 5$ & $1 / 7$ & $1 / 7$ & $1 / 9$ & 1 \\
\hline
\end{tabular}

Source: authors

Subsequently, individual values of the Saaty method were utilized for further calculations. The values obtained for the individual criteria in the intermediate calculations and the resulting values of the weighted geometric mean are shown in Table 4.

Values calculated by the Saaty method Table 4

\begin{tabular}{|c|c|c|c|}
\hline Criterion & $\begin{array}{c}\text { Multiples of } \\
\text { preferences }\end{array}$ & $\begin{array}{c}\text { Geometric } \\
\text { mean }\left(g_{i}\right)\end{array}$ & $\begin{array}{c}\text { Weighted } \\
\text { geometric } \\
\text { mean }\left(v_{i}\right)\end{array}$ \\
\hline$K 1$ & 37.5000 & 2.0640 & 0.2810 \\
\hline K2 & 3.1110 & 1.2550 & 0.1710 \\
\hline K3 & 0.0500 & 0.5490 & 0.0750 \\
\hline K4 & 3780.0000 & 3.2770 & 0.4460 \\
\hline K5 & 0.0004 & 0.2090 & 0.0270 \\
\hline$\sum$ & 418.6614 & 7.3540 & 1.0000 \\
\hline
\end{tabular}

Source: authors

\subsection{Selection of the most appropriate alternative using the particular method}

There are a lot of distinct methods to solve the multicriteria evaluation issues that can be utilized for the matter of particular alternative selection. However, a significant number of them cannot be applied, since they do not allow taking into consideration the entire complexity of these issues.

From the foregoing, it was decided to apply the Weighted Sum Approach method - WSA, which is suitable for the comprehensive issue of vehicle choice. The WSA method requires cardinal information, criteria matrix $Y$ and criteria weight vector $v$. 
The WSA method is able to create the overall rating for each of the alternatives and therefore, it can be utilized for selecting the most appropriate vehicle as well as for scaling the vehicles from best to worst [10,14 and 17].

Regarding this method, the weight of each criterion, i.e. $s_{v}=\left(v_{l}, v_{2}, \ldots, v_{k}\right)$ for $k$ of maximization criteria, is taken into consideration.

The WSA method then maximizes the weighted sum (see formula 3):

$u\left(A_{i}\right)=\sum_{j=1}^{k} v_{i} r_{i j}$.

where $u\left(A_{i}\right)$ is the aggregated utility function for each alternative, $v_{i}$ is the criteria weight vector (normalized geometric mean), $r_{i j}$ are the elements of the normalized criteria matrix. Hence, the value of the weighted sum for each alternative can be calculated and as a compromise alternative, the particular one with the greatest weighted sum can be selected [10, 11 and 18].

In the next step, it is necessary to create the criteria matrix. The rows of the criteria matrix are formed by the individual alternatives. The columns of the criteria matrix correspond to the individual criteria. In our case, the criteria matrix looks the same as Table 2.

Subsequently, it is inevitable to carry out the following steps:

1) Transformation of the criteria to the same type - it is important for all the criteria to be of the same type (minimization or maximization) [10 and 16].
2) Ideal and basal alternative - ideal alternative is the best option which may be practically achieved and basal alternative represents the worst possible alternative [5, 17 and 18].

3) Criteria matrix normalization - if the ideal and basal alternatives are known, the normalization of the criteria matrix may be simply carried out. In the criteria matrix, all the values are in the interval $\langle 0,1\rangle$, the ideal value of the criteria matrix is represented by the number 1 and the basal by the number 0 . A lot of studies on criteria matrix normalization are shown, for instance, in literature $[5,6,11$ and 19].

After creating the normalized criteria matrix, the aggregated utility function for each alternative " $u\left(A_{i}\right)$ " is calculated and alternatives are ranked from best to worst (see Table 5) [7 - 9, 20 - 22].

\section{Conclusions}

After completing the Saaty method, the greatest weight was assigned to the cargo space volume and the fuel consumption of the particular utility vehicle. After creating the criteria matrix with regard to the multi-criteria evaluation of alternatives, the individual vehicles were ranked from best to worst.

And therefore, on the basis of performed calculations, it may be concluded that the optimal vehicle type for cargo supply in particular urban traffic conditions seems to be an alternative $D 3$. On the other hand, alternative $D 5$ appears to be the least suitable selection that has the high fuel consumption and, compared to alternative D3 has insufficient cargo space volume [20 and 23].

Achieved results

\begin{tabular}{|c|c|c|c|c|c|c|c|}
\hline Alternative & Criterion & K1 & K3 & K4 & K5 & Order $\left(A_{i}\right)$ & \\
\hline$D 1$ & 0.772 & 0.591 & 0.654 & 0.540 & 0.218 & 0.614 & 2. \\
\hline$D 2$ & 1.000 & 1.000 & 0.073 & 0.000 & 1.000 & 0.484 & 3. \\
\hline$D 3$ & 0.877 & 0.000 & 1.000 & 1.000 & 0.000 & 0.767 & $\mathbf{1 .}$ \\
\hline$D 4$ & 0.702 & 0.553 & 0.000 & 0.353 & 0.330 & 0.458 & 4. \\
\hline Weightings & 0.000 & 0.445 & 0.055 & 0.237 & 0.907 & 0.210 & 5. \\
\hline
\end{tabular}

Source: authors

\section{References}

[1] BARATTA, V., FISCHER, M., WELTALMANACH, D.: Fischer Taschenbuch Verlag, Frankfurt am Main, 2001, ISBN 97-8359610385-0.

[2] FAZEKAS, M.: City Logistics, PhD Progress, University of Zilina, vol. 1, No. 2, 2013, 41-47, ISSN 1339-1712. 
[3] LIZBETINOVA, L., KAMPF, R., LIZBETIN, J.: Requirements of a Transport System User, Communications - Scientific Letters of the University of Zilina, vol. 14, No. 4, 2012, 106-108, ISSN 1335-4205.

[4] FAZEKAS, M., KUBASAKOVA, I., SULGAN, M.: Proposal of the City Logistics Solutions and Concepts for the City of Zilina, Logistics - Economy - Practice 2013, reviewed proc. of the $2^{\text {nd }}$ intern. Scientific conference, Zilina, 2013, 49-55, ISSN 13365851.

[5] JURKOVIC, M., SOSEDOVA, J.: Simulation Process of Optimal Transport Department Regarding to Transport Vehicles Based on AHP Method - Applied to Slovakia, Asian J. of Engineering and Technology, vol. 1, No. 4, 2013, 124-128, ISSN 2321-2462.

[6] ZOPOUNIDIS, C., PARDALOS, P.M.: Handbook of Multicriteria Analysis: Applied Optimization, vol. 103, 2010, SpringerVerlag Berlin: Heidelberg.

[7] EDWARDS, W.: The Theory of Decision Making, Psychological Bulletin, vol. 51, No. 4, 1954, 380-417.

[8] JABLONSKY, J.: Operations Research: Quantitative Models for Economic Decision Making, $3^{\text {rd }}$ ed., Professional Publishing : Prague, 2007, $323 \mathrm{p}$.

[9] ANDERSON, D. R., SWEENEY, D. J., WILliAMS, T. A., CAMM, J. D., KIPP MARTIN, R.: An Introduction to Management Science: Quantitative Approaches to Decision Making, South-Western College Pub., 2010, 1045 p.

[10] KALINA, T., JURKOVIC, M., BINOVA, H., GARDLO, B.: Water Transport - The Challenge for the Automotive Industry in Slovakia, Communications - Scientific Letters of the University of Zilina, vol. 18, No. 2, 2016, 26-29, ISSN 1335-4205.

[11] KEENEY, R., RAIFFA, H.: Decisions with Multiple Objectives, Preferences and Value Trade-offs, Cambridge University Press : Cambridge \& New York, 1976, 569 p.

[12] SAATY, T. L., VARGAS, L. G., WENDELL, R. E.: Assessing Attribute Weights by Rations, Omega - The Intern. J. of Management Science, vol. 2, No. 1, 1983, 9-13.

[13] LIZBETIN, J., CERNA, L., LOCH, M.: Model Evaluation of Suppliers in Terms of Real Company for Selected Criteria, Nase More, vol. 62, No. 3, 2015, 147-152. ISSN 0469-6255.

[14] SAATY, T. L.: Priority Setting in Complex Problems, Hansen, P. (Hrg.), Essays and Surveys on Multiple Criteria Decision Making. Proc. of the Fifth International Conference on Multiple Criteria Decision Making. Berlin : Heidelberg : NewYork : Springer-Verlag, 1983, $441 \mathrm{p}$.

[15] KAMPF, R., PRUSA, P., SAVAGE, C.: Systematic Location of the Public Logistic Centres in Czech Republic, Transport, vol. 26, No. 4, 2011, 425-432, ISSN 1648-4142.

[16] HRUSKA, R., PRUSA, P., BABIC, D.: The use of AHP Method for Selection of Supplier, Transport, vol. 29, No. 2, 2014, 195-203, ISSN 1648-4142.

[17] CABAN, J., DROZDZIEL, P., BARTA, D., LISCAK, S.: Vehicle Tire Pressure Monitoring Systems, Diagnostyka, vol. 15, No. 3, 2014, 11-14, ISSN 1641-6414.

[18] MALINDZAKOVA, M.: Significance Evaluation of Environmental Aspects, Communications - Scientific Letters of the University of Zilina, vol. 13, No. 3, 2011, 48-51, ISSN 1335-4205.

[19] SKRUCANY, T., SARKAN, B., GNAP, J.: Influence of Aerodynamic Trailer Devices on Drag Reduction Measured in a Wind Tunnel, Eksploatacja i niezawodnosc/Maintenance and Reliability, vol. 18, No. 1, 2016, 151-154, ISSN 1507-2711.

[20] FEDORKO, G., ROSOVA, A., MOLNAR, V.: The Application of Computer Simulation in Solving Traffic Problems. The Urban Traffic Management in Slovakia, Theor. Empir. Res. Urban Management, vol. 9, 2014, 5-17.

[21] ZITRICKY, V., GASPARIK, J., PECENY, L.: The Methodology of Rating Quality Standards in the Regional Passenger Transport, Transport Problems, vol. 10, 2015, 59-72, ISSN 1896-0596.

[22] POLIAKOVA, B.: Integrated Transport System Nodes and their Impact on the Increasing of Passenger Safety, Automotive Safety 2014: Problemy bezpeczenstwa w pojazdoch samochodowych: IX intern. science-technical conference : Rajecke Teplice : Kielce : Wydawnictwo Politechniki Swietokrzyskiej, 2014, 321-326, ISBN 978-83-63792-21-3.

[23] RHYS-TYLER, G. A., LEGASSICK, W., BELL, M. C.: The Significance of Vehicle Emissions Standards for Levels of Exhaust Pollution from Light Vehicles. An Urban Area, Atmospheric Environment, vol. 45, No. 19, 2011, 3286-3293, DOI:10.1016/ j.atmosenv.2011.03.035. 